\title{
Supporting Resilience and the Management of Grief and Loss: de Souza Program for Health Professionals
}

Mary Jane Esplen ( $\square$ maryjane.esplen@utoronto.ca )

University of Toronto https://orcid.org/0000-0002-6034-2235

Jiahui Wong

de Souza Institute

Mary Vachon

University of Toronto

Yvonne Leung

University of Toronto

Sarah Bakirci

University College London

\section{Research Article}

Keywords: grief and loss, compassion fatigue, resilience, burnout, educational program, health professionals

Posted Date: April 14th, 2021

DOI: https://doi.org/10.21203/rs.3.rs-330876/v1

License: (c) (i) This work is licensed under a Creative Commons Attribution 4.0 International License.

Read Full License 


\section{Abstract}

Health professionals in cancer care often face the challenge of stressful work environment, along with the impacts of providing care to those suffering from a life-threatening illness. Prevalence rates of compassion fatigue (CF) are moderate to high, yet health professionals have little knowledge on the topic.

Purpose: The objective of this study was to evaluate an educational program on knowledge of CF and strategies to support the management of grief and loss in practice.

Methods: A six-week program consisting of weekly video-conferencing sessions, case-based learning and an online community of practice was evaluated. Program content included personal, organization and team-related risk and protective factors associated with $\mathrm{CF}$, and strategies to mitigate against CF. Participants prepared personal plans. A standardized grief tool (RGEI) was given at baseline and pre and post surveys assessed confidence and knowledge and satisfaction.

Results: 189 health professionals completed the program ( $90 \%$ nurses). Patient loss in practices was high $(58.8 \%>10$ deaths annually; $12.2 \%>50)$. The program demonstrated significant improvement in confidence and knowledge across several domains $(p<0.05)$, including the use of grief assessment tools, risk factors for $\mathrm{CF}$, and strategies to mitigate against $\mathrm{CF}$. Personal plans varied from individual, team or organizational level strategies. Satisfaction ratings were high.

Conclusion: The results show benefit associated with an educational program that aims to improve knowledge of CF and assisted health care providers to develop personal plans/ strategies towards resilience. Further research is needed to assess longer term follow up and with designs that include a control group.

\section{Introduction}

Caring for patients with cancer is highly rewarding yet challenging for health professionals who often experience cumulative loss and deaths of their patients[1,2]. Exposure to suffering, dying and death is common which may contribute to the development of compassion fatigue (CF), a term used to describe the physical and emotional reactions as a result from caring for patients and bearing witness to pain and suffering $[2,3]$. The term "wounded healer" has been used to refer to the suffering carried by the healer as they care for their patients[4-6].

Zhang et al[7] in a meta-analysis of 21 studies found prevalence rate of $\mathrm{CF}$ at $52.55 \%$ among nurses. A study of medical oncologists showed that $51.2 \%$ suffered from emotional exhaustion, $31.8 \%$ from depersonalization, and $6.8 \%$ from a lack of personal accomplishment[8].

CF has received increased attention recently as it has been linked to reduced work-life satisfaction, as well as high attrition and increased absenteeism $[9,10]$. Quality of patient care can also be impacted[9]. 
Compassion fatigue (CF) is defined as a specific tension related to caring, which occurs through the reexperiencing of traumatic events and persistent arousal associated with the patient's suffering and distress[11, 12]. Common symptoms include: chronic exhaustion, reduced feelings of empathy, dreading working for, or taking care of another and feeling guilty thereafter[11, 12]. It may result in challenges in providing compassionate care to patients and thus impact quality of care[1].

\section{Background}

CF has previously been thought of in association with an empathic process, known as disruption in empathy[13]. Wilson and Lindy[14] described CF as an "intrusive" empathic strain between the clinician and client that can result in over-identification. For example, empathic strain is characterized by being distant and avoiding contact with the patient. These two states are not empathic in the therapeutic relationship; rather, they are dysfunctional processes[6, 15].

Many factors may contribute to the development of CF which include: lack of knowledge about CF, lack of support, and being unable to ease suffering[16]. Perez et al[17] in a qualitative study of palliative care practitioners identified three main areas of stressors for CF: (1) systematic challenges related to managing a large, emotionally demanding caseloads within time constraints; (2) patient factors, (e.g. meeting patient/family demands); and (3) personal challenges of maintaining emotional and professional boundaries. These stressors challenge a professional's effort to provide the desired level care, and may contribute to feelings of guilt and a sense of diminished competence[17].

Men may be more likely to experience depersonalization than women[16, 18]. Gleichgerrcht and Decety[18] found that gender had a highly selective effect on empathic concern, with women displaying higher values, which led to a wide array of negative and devalued feelings. Attachment style has also been investigated[19]. Insecure attachment is associated with impaired stress management and subtle deficits in professional care-giving sensitivity, especially as one is exposed to increased demands[20].

Protective factors have also been identified and include: peer support, sense of competence in workrelated tasks, work-life balance, connection and compassion towards self and others, acknowledgment of grief and loss in practice setting, knowledge about CF, maturity/experience, older age, and educational level[ $[7,13,16]$.

While knowledge and skill in self- care have been identified as important competencies in oncology[21], health professionals have little knowledge on the topic of $\mathrm{CF}$, or access to interventions to support resilience[16, 22]. Further, cultural and personal barriers can impede the reaching out for assistance [23, 24] and include feelings of shame, stoicism, the need to "be strong" and feelings of personal failure[16, 23]. A variety of intervention programs to prevent and help manage CF have been described [25].

Strategies include self-care wellness programs, education interventions, and the cultivation of healthcare providers personal qualities such as resiliency [25]. Opportunities for de-briefing in group sessions and the use of rituals have been suggested as a means for health professionals to come together as a team and to share in the expression around a loss, which may contribute to sense of meaning in the work[26]. 
Other programs have utilized resources such as mental health specialists to provide support [27]. More recently, there has been increased attention in the teaching of mindfulness stress reduction[28] or in methods to enhance skill in self and other compassion[6, 22, 24, 29].

A variety of educational programs have been designed to facilitate knowledge about $\mathrm{CF}$ and to support self-care $[25,27,30,31]$, as a preventive strategy that recognizes a lifelong approach to maintain the physical and psychological well-being [25]. As an example, Meadors and colleagues [31] developed an educational module to support self-care. Topics included CF definitions, symptoms, and strategies for reducing clinical stress. The program was evaluated, demonstrating benefit among health care providers working in pediatric intensive care units [31]. Other educational programs, such as The Accelerated Recovery Programme (ARP) includes information for recognizing CF symptoms and triggers, resources for countering $\mathrm{CF}$, and skill-building and tools to address the physical, behavioural and psychological demands while working in health care settings [30].

\section{Objective:}

The purpose of this study was to evaluate the impact of an online continuing educational program "Addressing Compassion Fatigue, Managing Grief and Loss Amongst Healthcare Professionals" as part of a quality improvement initiative to support front line health professionals providing oncology care.

\section{Materials And Methods}

\section{Design}

An educational program on CF was delivered by de Souza Institute via a virtual classroom. The Institute offers online courses, covering core competencies in oncology and/or palliative care and is linked to regional cancer centres across Canada. All courses integrate best practices and clinical guidelines to support Quality Improvement (QI) initiatives, and therefore, research ethics approval was not required for the evaluation. Participants in this education program were assessed on confidence and knowledge in core domain areas related to CF. At baseline participants also completed a grief inventory. A review of course online postings of case material and personal plans (required for course completion) was also completed.

\section{Participants}

Participants were 189 health professionals, with the majority (92.6\%) being nurses. Most participants were direct care clinicians; $10 \%$ were educators/managers/leaders.

\section{The Educational Intervention}

The program was developed by a PhD psycho-oncologist with experience in working with grief and loss. The primary aim of the program was to increase knowledge and confidence related to the impacts of exposure to suffering and loss, including understanding CF and burnout and recognition of types of grief 
experiences. The program was delivered on 14 occasions from 2011 to 2019. Continuing education credits were provided and could be used towards a "de Souza Designation"[21].

Format: Participants attended weekly 1.5-hour videoconference-based group sessions over six weeks. Each seminar included readings from the literature and was led by a PhD level practitioner/educator with experience in grief/ loss and psychotherapy. Weekly group discussions were further supported with an online community of practice for reflections and sharing of resources.

Content: The content was organized in relation to: personal, system/organization and team-related (interpersonal) factors contributing to CF, and strategies to support resilience. (see Table 1) The first three sessions focused on grief models and reactions, and definitions of burnout and CF. Personal risk factors associated with CF were reviewed, as well as contributing factors related to work settings or the team. Participants were encouraged to have a "working theoretical model of grief" to apply in their clinical work. As an example, readings were provided on the Dual Process Model of grief [32]. The topic of Medical Assistance in Dying (MAID) was also included.

The final three sessions focused on strategies and resources known to facilitate coping and that mitigate against CF. Participants worked towards a personal plan. These plans included strategies "they could do" to support their work/ team/ setting. Participants were encouraged to identify and consider how to address any relevant personal factors. In the final class, potential barriers to implementation of plans were identified and methods to address them.

Grief Experience: The Revised Grief Experience Inventory (RGEI)[33] was given as a self-assessment tool with a score for participants' own functioning. The RGEI was also used as a teaching aid. For example, the program leader reviewed the tool's items to illuminate specific domain areas for the assessment of grief reactions and for guidance in its application for assessing patients or caregivers. This exercise provided a type of mirroring experience, as participants reflected on personal experiences related loss (and associated personal reactions), while considering the application of the tool in relation to their clinical work.

Case-based learning: Prior to the first session, participants were asked to post the description of a "difficult case" that felt unresolved to them. Case narratives were reviewed and utilized during class discussions to illustrate variables (e.g. patient variables, health professional variable, work setting or context) that may have played a role in the sense of a lack of resolution. Participants were invited to reflect upon their cases throughout the course, applying their gained understanding of relevant factors that may have played a role, and invited to discuss what "they might do differently, if a similar situation presents once again".

\section{Measures:}

Demographics 
A demographic questionnaire at baseline collected information on demographics, including age, sex, profession, clinical work setting, and number of patient deaths over the past year and number of significant losses in the participant's personal life over the past five years.

\section{Revised Grief Experience Inventory (RGEI)}

To assess psychosocial functioning in relation to grief symptoms, the RGEI was given at baseline. The 22-item inventory has four domains: depression, existential concerns, guilt and physical distress. The instrument has been utilized in assessment of health professionals[34].

\section{Knowledge and Confidence in Managing Grief and Loss}

A self-report questionnaire to assess knowledge was developed by the research team and lead course educators with content expertise, and included items linked to learning objectives of the program. The survey was given before and after the course and consisted of 13 items with a 4-point Likert-type scale from Not knowledgeable at all (1) to Very knowledgeable (4). Item content included five domains: 1) Recognizing the Signs of burnout and CF and its Impacts; 2) Factors Contributing to Ability to Manage Loss; 3) Reflections on Experiences of Loss and Grief; 4) Strategies that Healthcare Professionals can integrate into their Practice; and 5) Team and Organization Strategies. A single item $10 \mathrm{~cm}$ Visual Analogue scale (VAS) was used to assess participant's confidence in the "ability to recognize and manage your own grief and loss", anchored with "not confident at all" to "very confident" pre and post the program.

\section{Personal Plans}

Participants posted and discussed personal plans. They were also asked to rate their intention to carry out specific activities to address grief and loss in relation to the following: i) apply self-assessment tools to identify loss and grief; ii) facilitate discussions with colleagues on issues of grief management and form a peer group with colleagues to obtain support for each other; iii) communicate to supervisor/manager about my grief and loss; iv) apply various stress management techniques to reduce distress and enhance coping; v) seek support from a mental health professional when having difficulties managing grief.

\section{Data Analysis}

Descriptive analysis was conducted. A step-wise regression analysis examined the association between demographic variables (age, sex, health profession, amount of loss in work setting and in personal life) and the baseline RGEl. A paired t-test was conducted (pre-post survey) to assess impact of the program on pre and post course confidence and knowledge measures. When handling missing items within a standardized measure, prorated scores were used if respondents had $<20 \%$ of the items missing. A content analysis was conducted using NVivo by the research team for open ended questions and reports related to participants' plans, with frequencies of each coding category reported. 


\section{Results}

A total of 189 healthcare professional learners enrolled into the program between 2011 and 2019. All learners completed the pre-course survey and returned the post-course survey with completed data.

The majority of participants were nurses and female (92.6\%). Approximately $16 \%$ of participants were younger than 29 years; $49 \%$ were between $30-49$ years of age and $32 \%$ were 50 or older. Participants reported a mean of 17.7 years of clinical practice, of which 7.3 years were in oncology. Approximately $38 \%$ worked in cancer centers, $23 \%$ in palliative care, $21 \%$ in community care and $18 \%$ in a general hospital unit. In relation to loss, $65 \%$ of participants experience 10 or more patient deaths in a typical year and $12.2 \%$ were exposed to more than 50 patient losses per year (See Table 2).

\section{Knowledge and Confidence}

At baseline, the total score on confidence and knowledge as measured by the 13 items was 35.30 $( \pm 12.01)$ on average. The average rating for individual items was $2.71( \pm 0.30)$, with the lowest rated score being for the item on "knowledge of self-assessment tools". Post- course, the total mean score increased to $41.06( \pm 16.60)$. Individual item average increased to 3.64 (maximum 4), with a standard deviation of 0.11. The pair t-test analysis indicted statistically significant improvement in all 13 items (See Figure 1). The change in total score was also statistically significant $[t(188)=4.02, p<0.05$ level]. A change from pre to post intervention on the single item (0 to 10) (VAS) assessing participant confidence in being able to recognize and manage grief and loss was also significant. Participants reported an average score of $9.2( \pm 1.0)$ post-program.

\section{Revised Grief Experience Inventory}

Using a cut off score (one standard deviation above the mean) to identify individuals who demonstrated significant grief symptoms, $18 \%$ of participants met this criteria (See table 3 ). The associations between baseline characteristics and RGEI were explored using regression analyses. The level of grief symptoms was not associated with the number of deaths in previous 12 months in participants' work environment.

\section{Personal Plans}

Specific strategies described among the personal plans included: facilitate peer support through increased awareness and discussions on CF with colleagues (78\%), organize peer support groups (78\%); carry out self-assessment on CF (61\%), enhance own coping through stress management strategies (78\%), seek professional help (40\%), open discussion with team or manager on grief and loss to address "culture"/organizational factors (42\%) (see Figure 2). More than $35 \%$ participants referred a colleague (s) to a subsequent de Souza course offering.

\section{Satisfaction}


Satisfaction with the program was high (85\%). Several participants suggested that this type of program should be provided earlier in their careers or during formal education (e.g. "This program should be encouraged during our education"; "I wish I had known all this earlier in my career"). Other participants expressed surprise at their gained insight concerning the role of personal factors (e.g., "I had no idea that my own personal factors could be playing so much a role"; "I didn't realize how little time I was taking to take better care of me; It's normal to not have everything work out well each time").

\section{Discussion}

At baseline, participants demonstrated a low level of awareness and confidence in the majority of items related to $\mathrm{CF}$, risk factors and strategies to mitigate against CF and that support coping with grief and loss. Pre post evaluation of the program demonstrated significant improvements in knowledge around a number of domain areas, including in the identification of risk factors or indicators for CF and burnout, knowledge of grief and its associated reactions, and personal self-care or team strategies that can be helpful to support resilience when working with suffering populations.

The majority of participants reported that the course provided the first opportunity to learn about personal risk factors. Most participants (90\%) at baseline reported contributing factors to CF as being primarily related to one's work setting (e.g. patient volume, time constraints). This perception changed over time to a broader view of contributing factors. Personal factors are relevant, particularly given the role of the "self" in providing supportive and psychosocial care[35]. Palliative care has been described by Barnard et al[36] as whole-person care, where the whole person of the caregiver is involved, requiring care that is given through the human relationship. Oncology, similarly, is at its best when delivering whole person care.

A significant number of participants $(75 \%)$ at baseline reported time pressures and a lack of resources in bringing the team together to explore issues in their work (50\%) as contributing to work strain.

Interestingly, more than $88 \%$ of participants reported that issues related to well-being are not raised during performance reviews. These findings are consistent with the literature and underline a work culture focused on patient and system outcomes[23]. Findings may also reflect personal and cultural barriers in expressing coping challenges among peers[16, 23]. In a qualitative study of oncologists, participants noted that the interviews were the first time they were asked about their coping[23].

Participants reported experiencing considerable loss in their practice settings. Sixty-five percent of participants experienced 10 or more losses in a typical year and $12.2 \%$ experienced more than 50 annually. Surprisingly, more than $80 \%$ of participants reported being unfamiliar with a model of grief. Only one-quarter (24\%) reported having formal or informal opportunity to address their experiences around loss in their settings. Opportunity for debriefs or rituals around patient deaths were reported more frequently among participants working in palliative care settings. However, consistent with the literature[17] time pressures or the lack of formal structures were also issues described in some palliative care settings. 
In examining the RGEI score, the mean in our sample was lower than that reported for primary caregivers of a dying patient[33], however, our sample mean was higher than that reported among a sample of pediatric nurses [34] (Table 3).

A sub-group of participants (18\%) in our study demonstrated a relatively high level of grief consistent with psychological suffering that would support the notion of "wounded healer" [6] and $26 \%$ of participants went to seek support from a grief counselor. In examining the RGEl score, the mean in our sample was lower than that reported for primary caregivers of a dying patient[33], however, our sample mean was higher than that reported among a sample of pediatric nurses [34] (Table 3). Several participants working in inpatient settings expressed strong emotions around cases traumatic in nature, concerning unexpected or untimely deaths (e.g., young patients). Fillion et al[37] studied Quebec nurses working in end of life care. Nurses working in critical care and oncology units reported high stress compared with specialized PC units[37]. Consistent with prior studies, the most common reported responses $(50 \%)$ were maintaining a need to 'carry on" $[16,23]$ and a stance of not expressing emotion. Some participants described the challenge of having to prepare the room for the next admission immediately following a death.

Participant comments indicated that the use of the grief inventory provided benefit in learning about specific domains (e.g., physical distress, depression) related to grief reactions. The strategy of having participants reflect on experiences with patients/families within their practices, along with their own wellbeing as they completed the grief tool was well-received. The group format was also reported as an ideal format (94\% of participants) and did not appear to hinder open and emotional expressions concerning personal experiences. Group intervention principles were utilized to support a culture of safety and confidentiality. Comments such as, "Seeing that others were having similar issues was surprising";" I learned so much from them" support a group-oriented approach to facilitate normalization and vicarious learning that may reduce stigma in expression of personal experiences around clinical work. Course leaders also disclosed around personal experiences. Several participants expressed valuing this aspect of the program (e.g., "I appreciate the leader disclosing, sharing and the openness of the forum").

\section{Limitations}

While findings from the program evaluation are consistent with benefit, there are some limitations to note. We did not include a control group for comparison. Further, while we utilized a standardized measure of grief at baseline, we did not include a standardized measure of $C F$, so were unable to assess the impact of the program on specific symptoms of CF. We also did not include a long-term follow-up to assess actual implementation of proposed plans.

\section{Conclusions}

In summary, an educational program designed to assist healthcare professionals to gain confidence and knowledge on CF strategies helpful to manage and address the impacts of loss experienced in clinical practice demonstrated benefit. Participants reported a low level of knowledge of CF at baseline, which 
improved following the program. The group format and the topics on personal, team-related, and organizational contributing factors to CF were well-received. All participants left the program with plans based on their learning, to support their work settings/ self-care. Further study is needed with a design that includes a comparison group and with longer term follow-up to further evaluate benefits of the program.

\section{Declarations}

\section{Funding}

This education program is supported by the de Souza Institute.

\section{Conflict of interest}

All authors have no conflict of interest to declare.

\section{Availability of data and material}

Data that support the findings of this study are available on request from the corresponding author.

Code availability: NA

\section{Authors' contributions}

All authors contributed to this paper. Dr. Mary Jane Esplen is the senior author and leader of the program. She led the selection of measures, evaluation and manuscript preparation. Dr. Jiahui Wong led the evaluation planning and implementation. Dr. Mary Vachon contributed to the content and delivery of the education program and the literature. Dr. Yvonne Leung contributed to the statistical analyses and data interpretation. Ms. Sarah Bakirci contributed to the literature review, data entry and management.

\section{Ethics approval}

This course is part of the continuing education curriculum at de Souza Institute. The content integrates best practices and clinical guidelines to support Quality Improvement (QI) initiatives, and therefore, research ethics approval was not required for the evaluation.

Consent to participate: NA

Consent for publication: NA

\section{Tables}

Table 1 Description of the Educational Program 


\begin{tabular}{|c|c|c|}
\hline Session & Topics & Course Strategies \\
\hline $\begin{array}{l}\text { Session } \\
\text { I }\end{array}$ & $\begin{array}{l}\text { Burnout and Compassion Fatigue } \\
\text { - Definitions } \\
\text { - Prevalence } \\
\text { - Symptoms }\end{array}$ & $\begin{array}{l}\text { - Posting of "difficult" case that felt } \\
\text { unresolved; } \\
\text { - Sharing/ discussion } \\
\text { - Assigned Readings } \\
\text { - Sharing in community of practice }\end{array}$ \\
\hline $\begin{array}{l}\text { Session } \\
\text { II }\end{array}$ & $\begin{array}{l}\text { Risk and Contributing Factors } \\
\text { - Health professional personal } \\
\text { Variables } \\
\text { - Patient Variables } \\
\text { - Team and Work Environment Factors }\end{array}$ & $\begin{array}{l}\text { - Lecture } \\
\text { - Assigned Readings } \\
\text { - Completion of RGEI Discussion } \\
\text { - Sharing in community of practice }\end{array}$ \\
\hline $\begin{array}{l}\text { Session } \\
\text { III }\end{array}$ & $\begin{array}{l}\text { Review of Grief Models } \\
\text { - Theory } \\
\text { - Grief Symptoms } \\
\text { - Assessment } \\
\text { - Importance of having a "working " } \\
\text { model of grief and loss }\end{array}$ & $\begin{array}{l}\text { - Lecture } \\
\text { - Assigned Readings } \\
\text { - Discussion } \\
\text { - Sharing in community of practice }\end{array}$ \\
\hline $\begin{array}{l}\text { Session } \\
\text { IV }\end{array}$ & $\begin{array}{l}\text { Strategies to Support Resilience / } \\
\text { Address Compassion Fatigue; } \\
\text { Prevention }\end{array}$ & $\begin{array}{l}\text { - Lecture } \\
\text { - Assigned Readings } \\
\text { - Discussion } \\
\text { - Sharing in community of practice }\end{array}$ \\
\hline $\begin{array}{l}\text { Session } \\
\text { V }\end{array}$ & $\begin{array}{l}\text { Strategies to Support Resilience / } \\
\text { Address Compassion Fatigue; } \\
\text { Prevention }\end{array}$ & $\begin{array}{l}\text { - Lecture } \\
\text { - Assigned Readings } \\
\text { - Discussion } \\
\text { - Sharing in community of practice }\end{array}$ \\
\hline $\begin{array}{l}\text { Session } \\
\text { VI }\end{array}$ & $\begin{array}{l}\text { Reconsideration of Posted Cases } \\
\text { from week 1; } \\
\text { Personal Plans going forward } \\
\text { (e.g personal well-being, team- } \\
\text { oriented plan; organization- oriented } \\
\text { plan). }\end{array}$ & $\begin{array}{l}\text { - Review of personal plans; } \\
\text { - Discussion and identification of } \\
\text { barriers/ enablers and strategies to } \\
\text { address them } \\
\text { - Discussion re posted case in week } 1\end{array}$ \\
\hline
\end{tabular}

Table 2 Participant Characteristics $(n=189)$ 


\begin{tabular}{|c|c|c|}
\hline & $\mathbf{N}$ & $\%$ \\
\hline \multicolumn{3}{|l|}{ Age } \\
\hline$<29$ & 30 & 15.93 \\
\hline $30-49$ & 92 & 48.7 \\
\hline $50+$ & 61 & 32.3 \\
\hline No answer & 6 & 3.2 \\
\hline \multicolumn{3}{|l|}{ Sex } \\
\hline Female & 175 & 92.6 \\
\hline Male & 7 & 3.7 \\
\hline No answer & 7 & 3.7 \\
\hline \multicolumn{3}{|l|}{ Profession } \\
\hline RN & 173 & 91.5 \\
\hline Other (i.e., social workers, radiation therapists, Occupational health) & 16 & 8.5 \\
\hline \multicolumn{3}{|l|}{ Clinical Setting } \\
\hline Cancer Centre, Cancer Clinic & 72 & 38.1 \\
\hline Hospice Palliative Care & 43 & 22.8 \\
\hline Home Care, Community Care & 40 & 21.1 \\
\hline General Hospital & 34 & 18.0 \\
\hline \multicolumn{3}{|l|}{ Percent of Cancer Patients } \\
\hline All are cancer patients & 64 & 33.9 \\
\hline More than half & 55 & 29.1 \\
\hline A third or less & 54 & 28.5 \\
\hline None & 4 & 2.1 \\
\hline No answer & 12 & 6.4 \\
\hline \multicolumn{3}{|l|}{ Seeing a Grief Therapist } \\
\hline $\mathrm{Y}$ & 46 & 24.3 \\
\hline \multicolumn{3}{|l|}{ \# Patient Deaths in previous year } \\
\hline$<10$ & 66 & 34.9 \\
\hline $10-29$ & 69 & 36.5 \\
\hline $30-49$ & 19 & 10.1 \\
\hline $50+$ & 23 & 12.2 \\
\hline No Answer & 12 & 6.4 \\
\hline \multicolumn{3}{|l|}{ Personal Loss (5 years) (answers not mutually exclusive) } \\
\hline Loss a close family member & 57 & 30.1 \\
\hline Loss a friend & 62 & 32.8 \\
\hline Loss a relative/co-worker & 51 & 27.0 \\
\hline Loss a pet & 35 & 18.5 \\
\hline No loss & 30 & 15.9 \\
\hline
\end{tabular}

Table 3 Revised Grief Experience Inventory (RGEI) Score 


\begin{tabular}{|r|l|l|l|}
\hline & $\begin{array}{l}\text { Lev's study with } \\
\text { primary care givers } \\
(\mathbf{N}=\mathbf{4 1 8})\end{array}$ & $\begin{array}{l}\text { Adwan's study with } \\
\text { pediatric nurses } \\
(\mathbf{N}=120)\end{array}$ & $\begin{array}{l}\text { Current educational } \\
\text { intervention } \\
\text { Participants } \\
(\mathbf{N}=189)\end{array}$ \\
\hline $\begin{array}{r}\text { Total score } \\
\text { Mean (SD) }\end{array}$ & $75.5(25.7)$ & $48.3(17.8)$ & $60.52(25.1)$ \\
\hline Range & $22-132$ & $22-94$ & $22-126$ \\
\hline Subscales & & $14.9(7.6)$ & $19.13(7.7)$ \\
\hline Depression & $23.0(7.0)$ & $15.1(6.3)$ & $18.34(8.2)$ \\
\hline $\begin{array}{r}\text { Physical } \\
\text { Distress }\end{array}$ & $22.5(9.3)$ & $11.1(4.8)$ & $14.5(7.8)$ \\
\hline $\begin{array}{r}\text { Existential } \\
\text { Concerns }\end{array}$ & $20.1(8.5)$ & & $8.6(3.9)$ \\
\hline $\begin{array}{r}\text { Tension } \\
\text { and Guilt }\end{array}$ & $10.0(4.6)$ & $7.3(2.8)$ & \\
\hline
\end{tabular}

Note:

1. Although not as high as primary care givers in palliative care, participants in de Souza course scored higher than pediatric nurses in Adwan's study;

2. $18 \%$ participants had total score $>85.5$ (de Souza course mean score +1SD);

3. 26\% had score > 75.5 (average total score Lev' primary care giver study);

$26 \%$ had seen a grief counselor

\section{References}

1. Engler-Gross A, Goldzweig G, Hasson-Ohayon I, Laor-Maayany R, Braun M (2020) Grief over patients, compassion fatigue, and the role of social acknowledgment among psycho-oncologists.

Psychooncology 29(3):493-499

2. Laor-Maayany R, Goldzweig G, Hasson-Ohayon I, Bar-Sela G, Engler-Gross A, Braun M (2020) Compassion fatigue among oncologists: the role of grief, sense of failure, and exposure to suffering and death. Support Care Cancer 28(4):2025-2031

3. Zajac LM, Moran KJ, Groh CJ (2017) Confronting Compassion Fatigue: Assessment and Intervention in Inpatient Oncology. Clin J Oncol Nurs 21(4):446-453

4. Larson D (2020) The Helper's Journey: Empathy, Compassion and the Challenge of Caring. Research Press, Champaign 
5. Mealer M, Jones J (2013) Posttraumatic stress disorder in the nursing population: a concept analysis. Nurs Forum 48(4):279-288

6. Vachon M, Harris D (2016) The Liberating Capacity of Compassion. In: Handbook of Social Justice in Loss and Grief D. Harris and T. Bordere, Editors. Routledge, New York, pp 265-281

7. Zhang Y-Y, Han W-L, Qin W, Yin H-X, Zhang C-F, Kong C, Wang Y-L (2018) Extent of compassion satisfaction, compassion fatigue and burnout in nursing: A meta-analysis. J Nurs Adm Manag 26(7):810-819

8. Eelen S, Bauwens S, Baillon C, Distelmans W, Jacobs E, Verzelen A (2014) The prevalence of burnout among oncology professionals: oncologists are at risk of developing burnout. Psycho-oncology 23(12):1415-1422

9. Panagioti M, Geraghty K, Johnson J, Zhou A, Panagopoulou E, Chew-Graham C, Peters D, Hodkinson A, Riley R, Esmail A (2018) Association Between Physician Burnout and Patient Safety, Professionalism, and Patient Satisfaction: A Systematic Review and Meta-analysis. JAMA internal medicine 178(10):1317-1330

10. Shanafelt TD, Mungo M, Schmitgen J, Storz KA, Reeves D, Hayes SN, Sloan JA, Swensen SJ, Buskirk SJ (2016) Longitudinal Study Evaluating the Association Between Physician Burnout and Changes in Professional Work Effort. Mayo Clinic proceedings, 91(4): 422-431

11. Figley CR (2002) Treating compassion fatigue. Brunner-Routledge, New York

12. Ray SL, Wong C, White D, Heaslip K (2013) Compassion Satisfaction, Compassion Fatigue, Work Life Conditions, and Burnout Among Frontline Mental Health Care Professionals. Traumatology 19(4):255-267

13. Vachon M, Huggard P, Huggard J (2015) Oxford Textbook of Palliative Nursing. In: Ferrell B, Coyle N, Paice J Reflections on occupational stress in palliative care nursingls it changing? Oxford University Press: New York, Editors

14. Wilson JP, Lindy JL (1994) Countertransference in the treatment of PTSD. Guilford, New York

15. Klimecki O, Singer T (2012) Empathic distress fatigue rather than compassion fatigue? Integrating findings from empathy research in psychology and social neuroscience. In: Oakley B et al Pathological altruism. Oxford University Press: New York, NY, US, Editors, pp 368-383

16. Turner J, Kelly B, Girgis A (2011) Supporting oncology health professionals: a review. PsychoOncologie 5(2):77-82

17. Perez GK, Haime V, Jackson V, Chittenden E, Mehta DH, Park ER (2015) Promoting Resiliency among Palliative Care Clinicians: Stressors, Coping Strategies, and Training Needs. Journal of Palliative Medicine 18(4):332-337

18. Gleichgerrcht E, Decety J (2013) Empathy in clinical practice: how individual dispositions, gender, and experience moderate empathic concern, burnout, and emotional distress in physicians. Plos one 8(4):e61526-e61526

19. Vachon M (2016) Attachment, Empathy and Compassion in the Care of the Bereaved. Grief Matters 19(1):20-25 
20. Adshead G (2010) Becoming a caregiver: attachment theory and poorly performing doctors. Medical education 44(2):125-131

21. Esplen MJ, Hunter J, Maheu C, Rosberger Z, Wong J, McGillicuddy P, Secord S, Blacker S, Green E, Toner B, Li J, Dobson K (2019) de Souza interprofessional practice cancer competency framework. Support Care Cancer 28(2):797-808

22. Kuhl D, Cave D, Pearson H, Whitehead P (2013) Treatment and prevention work: Center for practitioner renewal. In: Figley C, Huggard P, Rees CE First Do No Self-Harm: Understanding and promoting physician stress resilience. Oxford University Press: New York, Editors, pp 247-264

23. Granek L, Barbera L, Nakash O, Cohen M, Krzyzanowska MK (2017) Experiences of Canadian oncologists with difficult patient deaths and coping strategies used. Curr Oncol 24(4):e277-e284

24. Baranowsky A, Schmidt D (2013) Overcopers: Medical Doctor Vulnerability to Compassion Fatigue. In: Figley C, Huggard P, Rees CE First Do No Self Harm: Understanding and Promoting Physician Stress Resilience. Oxford University Press: New York, Editors, pp 203-215

25. Sinclair S, Kondejewski J, Raffin-Bouchal S, King-Shier KM, Singh P (2017) Can Self-Compassion Promote Healthcare Provider Well-Being and Compassionate Care to Others? Results of a Systematic Review. Appl Psychol Health Well Being 9(2):168-206

26. Wentzel D, Brysiewicz P (2017) Integrative Review of Facility Interventions to Manage Compassion Fatigue in Oncology Nurses. Oncology nursing forum 44(3):E124-E140

27. Boyle DA (2011) Countering compassion fatigue: a requisite nursing agenda. Online J Issues Nurs 16(1):2

28. Ghawadra SF, Abdullah KL, Choo WY, Phang CK (2019) Mindfulness-based stress reduction for psychological distress among nurses: A systematic review. Journal of clinical nursing 28(2122):3747-3758

29. Halifax J (2012) A heuristic model of enactive compassion. Curr Opin Support Palliat Care 6(2):228235

30. Flarity K, Gentry JE, Mesnikoff N (2013) The effectiveness of an educational program on preventing and treating compassion fatigue in emergency nurses. Adv Emerg Nurs J 35(3):247-258

31. Meadors P, Lamson A (2008) Compassion Fatigue and Secondary Traumatization: Provider Self Care on Intensive Care Units for Children. Journal of Pediatric Health Care 22(1):24-34

32. Stroebe M, Schut $H$ (2010) The dual process model of coping with bereavement: a decade on. Omega 61(4):273-289

33. Lev E, Munro BH, McCorkle R (1993) A shortened version of an instrument measuring bereavement. International journal of nursing studies 30(3):213-226

34. Adwan JZ (2014) Pediatric Nurses' Grief Experience, Burnout and Job Satisfaction. Journal of Pediatric Nursing: Nursing Care of Children Families 29(4):329-336

35. Badenoch B (2008) Being a brain-wise therapist. WW Norton, New York 
36. Barnard D, Towers A, Boston P, Lambrinidou Y (2000) Crossing Over: Narratives of Palliative Care. Oxford, New York

37. Fillion L, Desbiens JF, Truchon M, Dallaire C, Roch G (2011) Le stress au travail chez les infirmières en soins palliatifs de fin de vie selon le milieu de pratique. Psycho-Oncologie 5(2):127-136

\section{Figures}

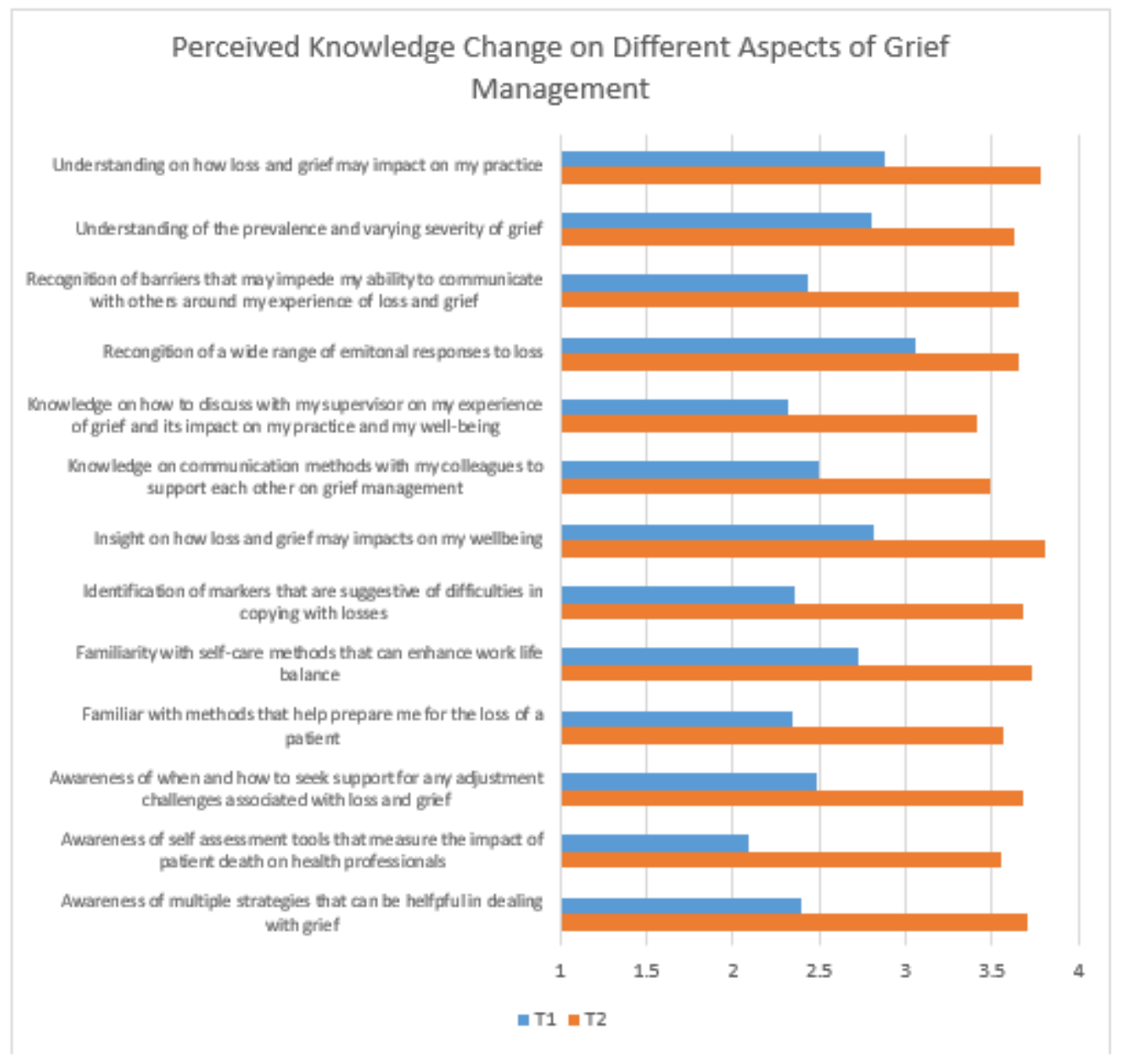

Figure 1

Perceived Knowledge Change ( $1=$ Not knowledgeable at all to $4=$ Very Knowledgeable) 
Reported Personal Plans Post Intervention

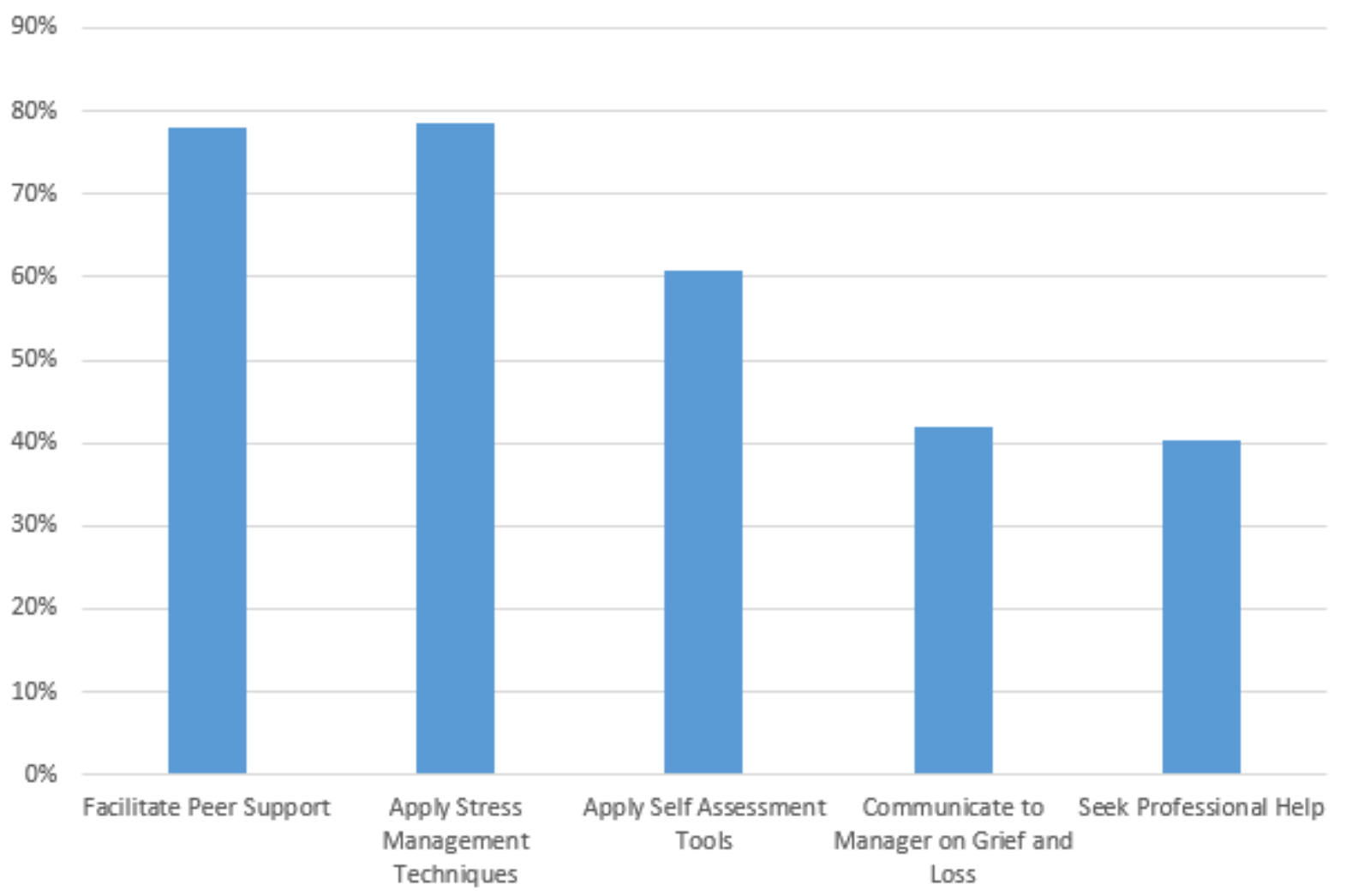

Figure 2

Strategies and personal plans to manage CF post intervention 